\title{
Bronchial Artery Embolization in Hemoptysis: 10-Year Survival and Recurrence-Free Survival in Benign and Malignant Etiologies - A Retrospective Study
}

\section{Bronchialarterienembolisation bei Hämoptysen: 10-Jahresüberleben und rezidivfreies Überleben bei benigner und maligner Genese - eine retrospektive Analyse}

Authors

Affiliations
R. Syha ${ }^{1}$, T. Benz ${ }^{1}$, J. Hetzel ${ }^{2}$, W. Spengler ${ }^{2}$, M. J. Kohlhäufl' ${ }^{3}$, S. Gatidis ${ }^{1}$, G. Grözinger ${ }^{1}$, M. Horger ${ }^{1}$, K. Nikolaou', D. Ketelsen ${ }^{1}$

Diagnostic and Interventional Radiology, University Hospital Tuebingen, Germany

2 Internal Medicine II, Department of Oncology, Haematology, Clinical Immunology, Rheumatology and Pneumology, University of Tuebingen, Germany

3 Center for Pulmonology and Thoracic Surgery, Division of Pulmonology, Klinik Schillerhoehe, Gerlingen, Germany
Key words

- broncial artery embolization

- subgroup analysis

- benign etiology

- malignant etiology received 25.4.2016

accepted $\quad 4.7 .2016$

Bibliography

DOI http://dx.doi.org/

10.1055/s-0042-112227

Published online: 2016

Fortschr Röntgenstr 2016; 188:

1061-1066 @ Georg Thieme

Verlag KG Stuttgart · New York .

ISSN 1438-9029

Correspondence

PD Dr. Dominik Ketelsen

Diagnostic and Interventional Radiology, University Hospital Tuebingen

Hoppe-Seyler-Str. 3

72070 Tuebingen

Germany

Tel.: ++49/70 71/2983371

email@dominik-ketelsen.de

\section{Zusammenfassung \\ $\nabla$}

Hintergrund: Ziel der Studie war die Evaluation der Bronchialarterienembolisation (BAE) in der Behandlung von Hämoptysen benigner oder maligner Genese bezüglich Sicherheit, Effektivität, Rezidivrate und der 10-Jahres-Überlebensrate. Material und Methoden: Die retrospektive Studie analysiert 100 BAE Prozeduren bei 88 Patienten. Die Grunderkrankung wurde als benigne $(n=67)$ oder maligne $(n=21)$ klassifiziert. Der technische Erfolg (sofortige Blutungskontrolle) und die Sicherheit der Prozedur wurde bei allen Patienten analysiert. Bei 51 Patienten (58\%) konnten Follow-up Daten mit einem medianen Follow-up von 1015 Tagen (range, 494 to 3727 Tagen) akquiriert werden (overall-survival, time-to-recurrence, recurrence-free survival), um Unterschiede zwischen den Subgruppen mittels Kaplan-MaierKurven zu analysieren.

Ergebnisse: Eine sofortige Blutungskontrolle konnte bei 96/100 Prozeduren erzielt werden. Die Minor-Komplikationsrate betrug $5,0 \%$ bei keinen Major-Komplikationen. Das Overall-survival betrug $74 \%$ nach einem Jahr und $59 \%$ nach 5 und 10 Jahren mit signifikanten Unterschieden zwischen der malignen und benignen Subgruppe $(p<0,0001)$. Das Overall-survival war $90 \%$ (1 Jahr), 80\% (3 Jahre) und 76\% (10 Jahre) in der benignen und 18\% (1 Jahr) und $0 \%$ (3 Jahre) in der malignen Subgruppe. Die mittlere time-to-recurrence und das recurrencefree-survival war 239 Tage und 94\% nach $1 \mathrm{Jahr}$ und $87 \%$ nach 10 Jahren (benigne Subgruppe) verglichen zu 66 Tagen und 34\% nach $1 \mathrm{Jahr}$ und $0 \%$ nach 3 Jahren (maligne Subgruppe) $(\mathrm{p}=0,0107)$.

Schlussfolgerung: Die BAE ist eine sichere und effektive Therapieoption bei Hämoptysen. Der Langzeiterfolg ist jedoch abhängig von der Grunderkrankung.

\section{Abstract \\ $\nabla$}

Purpose: The aim of the study was to evaluate safety, effectiveness, recurrence rate and 10-year survival after bronchial artery embolization (BAE) in benign and malignant etiologies.

Methods: The retrospective study includes 100 BAE procedures in 88 patients. Underlying disease was classified as benign $(n=67)$ and malignant $(n=21)$ etiologies. Immediate bleeding control and procedure safety were evaluated in all patients. In $51(58 \%)$ patients, follow-up data with a median follow-up time of 1015 days (range, 494 to 3727 days) were acquired to assess overall survival, time-to-recurrence of bleeding and recurrence-free survival, using Kaplan-Maier estimates to compare differences between both subgroups.

Results: Immediate bleeding control was achieved after $96 / 100$ procedures (96\%), with a minor complication rate of $5.0 \%$. No major complications occurred. The overall survival was $74 \%$ after 1 year and $59 \%$ after 5 years and 10 years. There was a significant difference in survival between the malignant and benign groups ( $p<0.0001$ ). Survival was $90 \%, 80 \%$ and $76 \%$ at 1 year, 3 years and 10 years, respectively, in the benign group and $18 \%$ and $0 \%$ at 1 year and 3 years, respectively in the malignant group. The median time to recurrence of bleeding and recurrence-free survival were 239 days and $94 \%$ after 1 year and $87 \%$ after 10 years in the benign group, compared to 66 days and $34 \%$ after 1 year and $0 \%$ after 3 years in the malignant group ( $\mathrm{p}=0.0107)$.

Conclusion: BAE is a safe and highly effective treatment option in hemoptysis. However, the recurrence rate and survival are highly dependent on the underlying disease. 
Kernaussagen:

$\checkmark$ Die BAE ist eine sichere und effektive Therapieoption bei Hämoptysen.

> Die Rezidivrate und das Überleben nach BAE ist abhängig von der Grunderkrankung mit signifikant schlechteren Ergebnissen bei maligner Ätiologie.

Die Coilembolisation ist eine effektive Möglichkeit der BAE. Jedoch muss darauf hingewiesen werden, dass eine inital zentrale Embolisation der Bronchialarterie zu vermeiden ist, um Reinterventionen zu ermöglichen.
Key Points:

BAE is a safe and highly effective treatment option in hemoptysis.

- Recurrence rate and survival are strongly dependent on the underlying disease with significantly impaired results in patients with malignant diseases.

$>$ Coil embolization is an effective BAE treatment method. Nevertheless, it should be mentioned, that reinterventions can be impeded, if embolization is performed in the proximal part of bronchial arteries.

Citation Format:

- Syha R, Benz T, Hetzel J et al. Bronchial Artery Embolization in Hemoptysis: 10-Year Survival and Recurrence-Free Survival in Benign and Malignant Etiologies - A Retrospective Study. Fortschr Röntgenstr 2016; 188: 1061-1066

\section{Introduction}

$\nabla$

Hemoptysis is a potentially life-threatening emergency situation requiring immediate diagnosis and therapy. Bronchial artery embolization (BAE) has been established as the minimally invasive therapy of choice for recurrent and massive hemoptysis, as surgical therapy in hemoptysis has a reported mortality rate between $7 \%$ and $18 \%$, and up to $45 \%$ in the emergency setup [1, 2]. The most common indications for BAE are tuberculosis, bronchiectasis, cystic fibrosis, and various malignant etiologies. Only in a minority of cases, hemoptysis is caused by bleeding of pulmonary arteries, such as aneurysm bleeding or pulmonary arterio-venous fistulas [3].

The technical success and effectiveness of BAE in the management of hemoptysis is well described, with high rates of immediate bleeding control in chronic, recurrent and massive hemorrhage [4]. Long-term control rates are variable and are influenced by the etiology of hemoptysis [5]. However, most reports of BAE in hemoptysis are focused on benign etiologies and research about effectiveness in patients with a malignant etiology as a separate subgroup as well as long-term outcome data are rare $[4,6]$. The aim of this retrospective study was to evaluate immediate bleeding control, recurrence rate and 10-year survival after BAE in benign and malignant etiologies and to compare differences between these subgroups. In addition, pre-interventional CT findings, angiographic findings of the bleeding site and complication rates of the BAE procedure were assessed.

\section{Materials and Methods}

$\nabla$

Patient population

Institutional review board approval was obtained for this retrospective study. Between 04/2000 and 09/2015, a total of 103 BAEs were performed in 91 patients (median age: 59 years, range: 40 to 73 years) suffering from mild, moderate and severe hemoptysis. 3 patients were excluded from the retrospective analysis because of missing data. Therefore, 100 BAEs in 88 patients were included in the retrospective analysis. Bleeding severity was stratified as follows: Mild hemoptysis means clinically significant or recurrent bleeding without a need for bronchoscopy tamponade, and moderate hemoptysis was defined in patients with bronchoscopy-guided tamponade prior to BAE procedure. In patients with severe hemoptysis, broncho- scopy-guided tamponade and tracheal intubation were performed prior to BAE as standard of care in our institution.

Underlying diseases were vascular malformations ( $n=13)$, inflammatory pulmonary diseases $(n=9)$, cystic fibrosis $(n=8)$, undergone tuberculosis $(n=8)$, lung metastases $(n=8)$, bronchial carcinoma $(n=6)$, aspergillosis $(n=5)$, lymphoma $(n=5)$, idiopathic $(n=22)$, or other $(n=4)$. Based on these underlying diseases, patients were sub-classified as suffering from benign ( $n=67$ including idiopathic disease) or malignant $(n=21)$ etiologies.

As standard of care, prior to BAE, bronchoscopy and/or contrastenhanced computed tomography (CT) was performed in all patients to identify the bleeding location and the underlying disease.

Immediate bleeding control (short-term follow-up) was defined as bleeding control during hospitalization and was evaluated in all patients (100\%). A long-term follow-up assessment by search of the medical records could be performed in 51 patients (58\%), with a median follow-up time of 1015 days (range: 494 to 3727 days), to assess overall survival and recurrence of hemoptysis. Complications were also reported by search of medical records and, if available, by follow-up CTs. Complications that resulted in permanent adverse sequelae or death were classified as major complications, and the remaining complications as minor.

Pre-interventional CT imaging was available in 64 cases. Angiograms were archived in 85/100 cases. In 15/100 cases, angiographic images were not available. These were interventions performed before 2005. After that time point, installation of a digital picture archiving and communication system (PACS) ensured consistent data storage.

\section{Angiography and bronchial artery embolization}

The arterial system was accessed through the right common femoral artery. A 4F sheath (Terumo, Leuven, Belgium) was placed. In the case of an unclear origin of the bronchial arteries, an aortography was performed using $4 \mathrm{~F}$ pigtail configured catheters. For access to bronchial arteries, C2, SIM1, SOS, or H1 configured catheters were used. Selective angiography and intubation were performed using a 2,7F microcatheter (Progreat, Terumo, Leuven, Belgium). Embolic agents were coils $(n=68)$, histoacryl $(n=19)$, PVA agents $(n=1)$, vascular plugs $(n=1)$, or combinations of different agents $(n=11)$, according to the preference of the interventional radiologist, as well as the site of bleeding and vessel size. Successful embolization was defined as complete devascularization of the treated peripheral bronchial artery system. 


\section{Angiogram and $\mathrm{CT}$ assessment}

All angiograms and computed tomography images were assessed by two board certified interventional radiologist in consensus reading. The location (right, left, bilateral) and distribution (focal, diffuse) of the bleeding according to the CT findings were documented. Further $\mathrm{CT}$ findings concerning the lung and thorax were classified as consolidation, ground-glass opacity, fungal balls, tuberculous destroyed lung parenchyma, hypertrophied vessels, emphysema, bronchiectasis, abscess, primary lung tumor/bronchial carcinoma, and metastasis.

The location of the findings in the angiograms was also documented (right, left, and bilateral). Angiographic findings were defined as broncho-pulmonary artery shunt, hypertrophied vessels, neo-vascularization, and active bleeding. The number and origins of treated bronchial arteries were documented. All angiograms of patients treated with coils were assessed with respect to the location of coil embolization (peripheral, central or both). Peripheral embolization was preferred. Central embolization was performed due to anatomical considerations or in the case of recurring bleeding.

\section{Statistics}

Statistical analysis was performed using the statistical software package JMP 11.1.1 (SAS, Cary, United States). Interval data are expressed as mean and range. Recurrence rates and survival rates were analyzed and compared using Kaplan-Meier survival analysis. The overall survival and time to recurrence were calculated. P-values below 0.5 were considered significant. Normal distribution was assessed using the Kolmogorov-Smirnov test. A Wilcoxon signed rank test was used for the comparison of non-normally distributed numerical data. For categorical data Fisher's exact test was used to test for significant differences.

\section{Results}

\section{Overall results}

85 angiograms and 64 CTs were analyzed with respect to the location and extent of pathologic findings. Detailed information about pre-interventional $\mathrm{CT}$, angiographic findings and bleed- ing severity in benign and malignant diseases are summarized in 0 Table 1, 2.

Most common CT findings were consolidation (61\%) and ground-glass opacity (72\%), with comparable results in the benign as well as the malignant group ( 0 Table 1 ). Fisher's exact test revealed no significant differences for different CT findings besides the finding "primary lung tumor/bronchial carcinoma" $(p=0.0014)$ and the finding "metastasis" $(p<0.0001)$, which were naturally only present in the malignant group.

Angiographic findings showed active bleeding in only $16 \%$ of cases whereas neo-vascularization ( $85 \%$ ) and vessel hypertrophy $(45 \%$ ) were the most common findings ( 0 Table 2, 0 Fig. 1 ). Most patients were treated by coil embolization $(68 \%)$ and histoacryl (19\%) (৫ Table 2). Successful embolization could be achieved in all patients (complete devascularization of peripheral bronchial artery system). Immediate bleeding control (short-term follow-up) during hospitalization was achieved after 96/100 procedures (96\%). In 4 patients without immediate bleeding control, the underlying disease was malignant in 2 cases (metastasis, $\mathrm{n}=2$ ) and benign in 2 cases. This resulted in immediate bleeding control of $97 \%$ in the benign group and $90 \%$ in the malignant group. 3 patients without immediate bleeding control were initially treated with coils $(3 / 68,5 \%)$. The fourth patient was initially treated with histoacryl $(1 / 19$, $5 \%$ ). All cases of persistent bleeding could be successfully treated by a second BAE. In two cases, retreatment was performed with coils, one patient received a vascular plaque, and one patient was retreated with histoacryl.

Regarding angiograms $(n=62)$ of the subpopulation who received coil embolization, the embolization location was peripheral $(n=46,75 \%)$, central or both $(n=16,25 \%)$. Either central embolization or embolization in both locations $(n=16)$ was performed in secondary interventions (5/16) after initial peripheral embolization. In 11/16 cases central embolization or embolization in both locations was initially performed due to anatomical considerations. All recurrent bleeding in the coil group occurred in patients with initial peripheral embolization.

Minor complications of the BAE procedure occurred after 5 procedures (5.0\%): 1 patient suffering from peri-interventional transient aphasia with complete restitution, 1 iatrogenic

\begin{tabular}{|c|c|c|c|}
\hline & & etiology & \\
\hline & total & benign & malignant \\
\hline number of CTs & 64 & $45(70 \%)$ & $19(30 \%)$ \\
\hline \multicolumn{4}{|l|}{ lung involvement } \\
\hline focal/diffuse & $33(52 \%) / 31(48 \%)$ & $25(56 \%) / 20(44 \%)$ & $8(42 \%) / 11(58 \%)$ \\
\hline left & $11(17 \%)$ & $10(22 \%)$ & $1(5 \%)$ \\
\hline right & $30(47 \%)$ & $20(44 \%)$ & $10(53 \%)$ \\
\hline bilateral & $18(28 \%)$ & $11(24 \%)$ & $7(37 \%)$ \\
\hline none & $5(8 \%)$ & $4(9 \%)$ & $1(5 \%)$ \\
\hline \multicolumn{4}{|l|}{ CT findings } \\
\hline fungal balls & $5(8 \%)$ & $4(9 \%)$ & $1(5 \%)$ \\
\hline tuberculous-destroyed & $2(3 \%)$ & $2(4 \%)$ & 0 \\
\hline hypertrophied vessel & $16(25 \%)$ & $13(29 \%)$ & $3(16 \%)$ \\
\hline consolidation & $39(61 \%)$ & $26(58 \%)$ & $13(68 \%)$ \\
\hline ground glass opacity & $46(72 \%)$ & $32(71 \%)$ & $14(74 \%)$ \\
\hline emphysema & $15(23 \%)$ & $11(24 \%)$ & $4(21 \%)$ \\
\hline bronchiectasis & $25(39 \%)$ & $16(36 \%)$ & $9(47 \%)$ \\
\hline abscess & $3(5 \%)$ & $2(4 \%)$ & $1(5 \%)$ \\
\hline bronchial carcinoma & $5(8 \%)$ & 0 & $5(26 \%)$ \\
\hline metastasis & $10(16 \%)$ & 0 & $10(53 \%)$ \\
\hline
\end{tabular}

Table 1 CT findings before bronchial artery embolization in benign and malignant etiology.

Tab. 1 CT-Befunde bei benigner und maligner Grunderkrankung vor BAE. 


\begin{tabular}{|c|c|c|c|}
\hline & \multicolumn{3}{|c|}{ etiology } \\
\hline & total & benign & malignant \\
\hline number of angiograms & 85 & $62(73 \%)$ & $23(27 \%)$ \\
\hline \multicolumn{4}{|l|}{ embolization site } \\
\hline left lung & $22(26 \%)$ & $19(30 \%)$ & $3(13 \%)$ \\
\hline right lung & $50(59 \%)$ & $33(53 \%)$ & $17(74 \%)$ \\
\hline bilateral & $13(15 \%)$ & $10(16 \%)$ & $3(13 \%)$ \\
\hline \multicolumn{4}{|l|}{ angiographic findings } \\
\hline broncho-pulmonary artery shunt & $24(28 \%)$ & $18(29 \%)$ & $6(26 \%)$ \\
\hline vessel hypertrophy & $38(45 \%)$ & $27(44 \%)$ & $11(48 \%)$ \\
\hline neo-vascularization & $72(85 \%)$ & $52(84 \%)$ & $20(87 \%)$ \\
\hline active bleeding & $14(16 \%)$ & $9(15 \%)$ & $5(22 \%)$ \\
\hline \multicolumn{4}{|l|}{ number of vessels treated } \\
\hline 1 & $66(78 \%)$ & $47(76 \%)$ & $19(83 \%)$ \\
\hline$>1$ & $19(22 \%)$ & $15(24 \%)$ & $4(17 \%)$ \\
\hline \multicolumn{4}{|l|}{ location of vessel(s) } \\
\hline thoracic aorta & $81(94 \%)$ & $60(95 \%)$ & $21(91 \%)$ \\
\hline phrenic artery & $1(1 \%)$ & $1(2 \%)$ & 0 \\
\hline internal mammary artery & $4(5 \%)$ & $2(3 \%)$ & $2(9 \%)$ \\
\hline number of embolizations & 100 & $75(75 \%)$ & $25(25 \%)$ \\
\hline \multicolumn{4}{|l|}{ bleeding severity } \\
\hline mild & & $35(47 \%)$ & $9(36 \%)$ \\
\hline moderate & & $33(44 \%)$ & $9(36 \%)$ \\
\hline severe & & $7(9 \%)$ & $7(28 \%)$ \\
\hline \multicolumn{4}{|l|}{ embolic agent } \\
\hline coils & $68(68 \%)$ & $53(71 \%)$ & $15(60 \%)$ \\
\hline histoacryl & $119(19 \%)$ & $14(19 \%)$ & $5(20 \%)$ \\
\hline PVA agent & $1(1 \%)$ & $1(1 \%)$ & 0 \\
\hline vascular plug & $1(1 \%)$ & 0 & $1(4 \%)$ \\
\hline combination & $11(11 \%)$ & $7(9 \%)$ & $4(16 \%)$ \\
\hline
\end{tabular}

Table 2 Angiographic findings, number of treated vessels and their location as well as embolic agent as a function of underlying disease.

Tab. 2 Angiographische Befunde, Anzahl der behandelten Gefäße und deren Lokalisation und Embolisationsmaterial in Abhängigkeit der Grunderkrankung. perforation of the left bronchial artery which could be immediately treated by coil embolization, and 3 patients needed medical treatment because of prolonged chest pain. No major complications occurred.

\section{Survival analysis}

A follow-up was available in 51 patients (58\%) with a median follow-up time of 33 months (interquartile range: 9 to 123 months). The overall survival rate of the study population was $74 \%$ after 1 and 2 years, $64 \%$ after 3 years, and $59 \%$ after 4 , 5 , and 10 years. For detailed information, see $\bullet$ Fig. 2 A (Kaplan Meier survival curve).

The Kaplan Meier estimate showed a significant difference in survival between the malignant and benign groups $(p<0.0001)$. This resulted in a 6 -month and 1 -year survival rate of $18 \%$ in the malignant group and a 3-year survival rate of $0 \%$. The benign group showed a 1-year and 2-year survival rate of $90 \%$, a 3-year survival rate of $80 \%$, as well as a 4-year, 5-year, and 10-year survival rate of $76 \%$. Detailed information on these survival rates is given in 0 Fig. 2B.

\section{Recurrence of hemoptysis}

Regarding patients with follow-up $(n=51)$, hemoptysis after primarily successful embolization recurred in 10/51 patients (20\%) with a median time to recurrence of 66 days (interquartile range: 13 to 610 days). Re-bleeding was treated in $8 / 10$ cases by embolization ( $80 \%$ ) with immediate bleeding control in all cases. $1 / 10$ patients $(10 \%)$ died due to recurrent bleeding (benign group) and 1 patient was treated elsewhere. The underlying disease in this single case was chronic heart failure (cardiac assist device) with recurring cardiac decompensation. The other 9 patients suffered from lung metastases $(n=4)$, vascular malformations $(n=2)$, aspergillosis $(n=2)$, and status post tuberculosis $(n=1)$. Overall recurrence-free survival was $89 \%$ after 1 year, $87 \%$ after 2 and 3 years, and $82 \%$ after 5 as well as 10 years. The results of the Kaplan Meier analysis are presented in $\bullet$ Fig. $2 C$. The subgroups showed a significantly higher recurrence rate of bleeding in the malignant subgroup compared to the benign subgroup $(p=0.0107)$. The median time to recurrence was 239 days (interquartile range: 13 to 1241 days) in the benign group and 66 days (interquartile range: 12 to 91 days) in the malignant group. Recurrence-free survival in the benign group was $94 \%$ after 1 year, $92 \%$ after 2 and 3 years, and $87 \%$ after 5 as well as 10 years. Recurrencefree survival in the malignant group was $34 \%$ after 1 year. The respective Kaplan Meier curves are presented in $\bullet$ Fig. 2 D.

\section{Discussion}

$\nabla$

Clinically significant, chronic and recurrent hemoptysis is a potentially life-threating disease and BAE is a widely used and established minimally invasive procedure [7].

In this study, immediate bleeding control defined as clinical success during the hospital stay was achieved in $96 \%$ of patients. All cases of persistent bleedings $(n=4)$ were successfully treated by a second BAE. The underlying disease in patients without initial immediate bleeding control was metastasis $(n=2)$ and of benign etiology $(n=2)$, resulting in immediate bleeding control of $97 \%$ in the benign group and $90 \%$ in the malignant group. These results are comparable to previously reported immediate bleeding control rates of $75-98 \%[4,8]$.

A retrospective analysis in 120 patients with hemoptysis showed a majority of cases of bleeding in the right lung (62\%) 

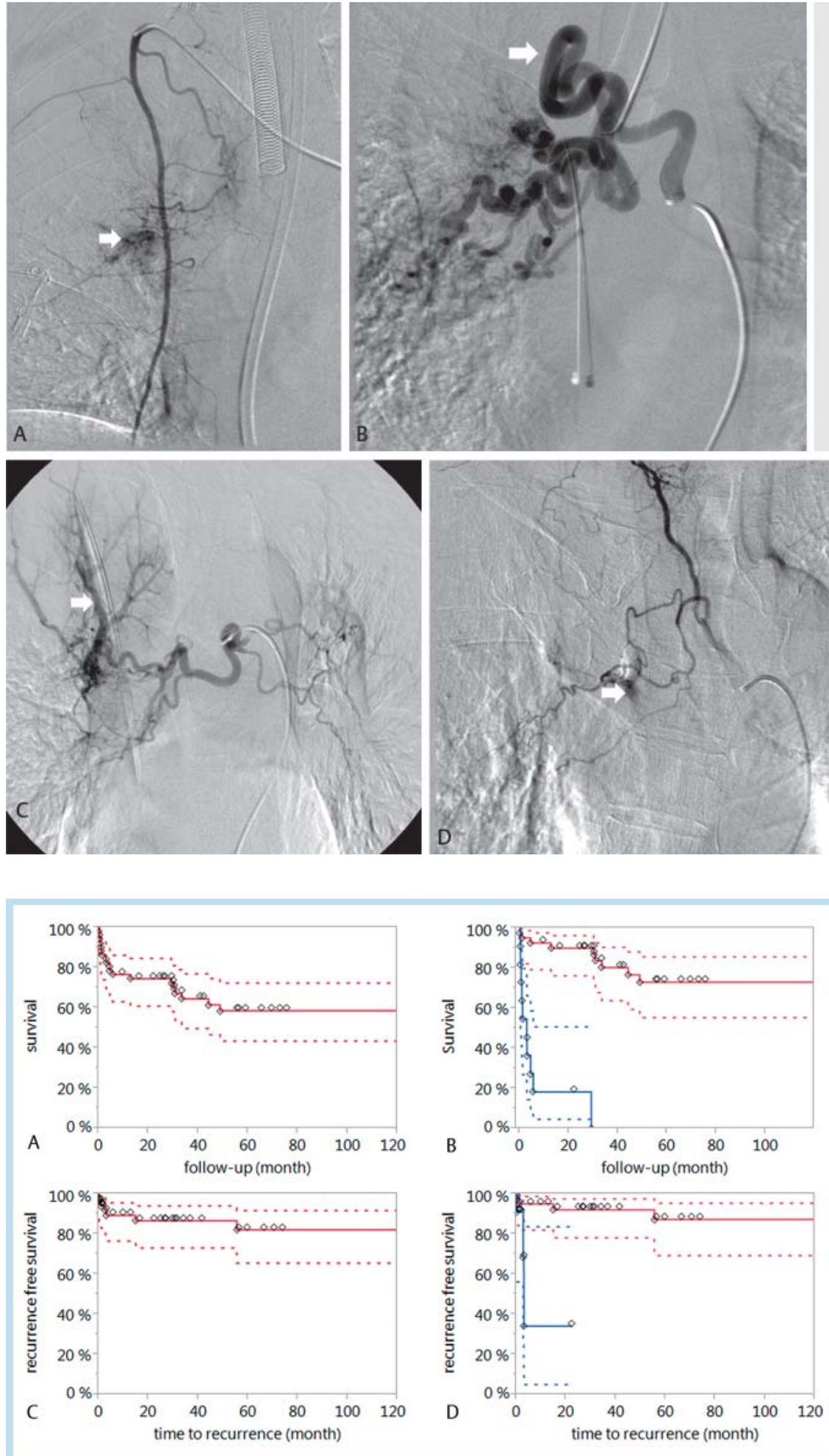

Fig. 1 Exemplary angiographic findings (arrows) in BAE procedure showed neo-vascularization (A: metastasis, 75-year-old male), vessel hypertrophy (B: cystic fibrosis, 40-year-old female), broncho-pulmonary artery shunt (C: aspergilloma, 44-year-old female), and active bleeding (D: post tuberculosis, 40-year-old female). Bleeding source was the right bronchial artery B-D and right internal mammary artery $\mathbf{A}$, respectively.

Abb. 1 Die exemplarischen angiografischen Befunde der BAE-Prozeduren zeigen eine Neovaskularisation (A, Metastasen, 75-jähriger Mann), eine Gefäßhypertrophie (B, Cystische Fibrose, 40-jährige Frau), einen broncho-pulmonalen Shunt (C, Aspergillom, 44-jährige Frau) und eine aktive Blutung (D, Z. n. Tuberkulose, 40-jährige Frau). Die Blutungsquelle war die rechte Bronchialarterie B-D bzw. die rechte $\mathbf{A}$. mammaria interna $\mathbf{A}$. compared to the left lung (38\%) [2]. Our angiographic data have also shown more frequent bleeding on the right side (59\%). Despite high rates of immediate bleeding control, the long-term control rate is highly dependent on the underlying disease. In general, benign etiologies respond better to BAE as compared to malignant diseases causing hemoptysis [4, 9-11]. In benign underlying disease, aspergillomas have the least favorable long-term response to BAE, and often surgery is mandatory for permanent bleeding control [4]. Our results are consistent with previous reports and showed a significantly better outcome
Fig. 2 Kaplan-Maier curves show overall survival (A: red line) and overall time to recurrence (C: red line). Overall survival $\mathbf{B}$ and time to recurrence $\mathbf{D}$ for the benign (red lines) and the malignant (blue lines) subgroups are also provided. Confidence intervals are given (dotted lines). The black diamonds mark the censored cases.

Abb.2 Die Kaplan-Maier Kurven zeigen das overal survival (A, rote Linie) und die time-to-recurrence (C, rote Line). Das overall survival und die time-torecurrence der benignen (rote Linie, B, D) und der malignen (blaue Linie, B, D) Subgruppe ist ebenfalls dargestellt. Die gestrichelten Linien stellen die Konfidenzintervalle dar, die schwarzen Rauten zensierte Fälle. 
or a recurrence rate of up to $100 \%$ in patients with aspergillomas [4]. The median time to recurrence was 239 days in the benign group and 66 days in the malignant group. The shorter time period of 66 days in malignant disease is presumably caused by a more rapid disease progression in the malignant group. Only 1 patient died due to recurrent bleeding because of cardiac decompensation in chronic heart failure.

The overall survival showed a 1 -year survival of $74 \%$ at 1 year, and $59 \%$ at 5 years and 10 years. Significant differences occurred between the two subgroups, resulting in survival of $90 \%$ at 1 and 2 years and $76 \%$ at 5 and 10 years in the benign group compared to a survival rate of $18 \%$ at 1 year and $0 \%$ at 3 years in the malignant subgroup. These rates were comparable with previous reports $[4,13]$.

At present, there is no consensus as to which embolic agent is the most effective. Reports include gelatin sponges, PVA particles, Nbutyl-2-cyanocrylate (NBCA, histoacryl), and coils, with bleeding control rates being higher with NBCA than with PVA or gelatin sponges [14]. Coils are described as suboptimal when embolization is performed in the proximal part of bronchial arteries, as re-intervention might be impeded. However, several studies showed no significantly inferior outcome with the use of coils as the embolic agent $[11,15]$. The embolic agent used in this study depended on the preference of the interventional radiologist, and most patients were treated by coil embolization (68\%) and NBCA (19\%), without differences in intermediate bleeding control (5\% recurrence for both). However, all patients without immediate bleeding control could be treated successfully in a second BAE, even patients after prior coil embolization due to preferred peripheral coil embolization in the initial procedure. Nevertheless, in our patients who received a central coil embolization due to anatomical considerations or reintervention, no recurrence of bleeding was seen. As only a few cases of BAE were embolized in only a central position, these results are limited and primary central embolization cannot be recommended on the basis of this data. Moreover, statistical differences between the embolization agents (coils, PVA, histoacryl) cannot be assessed because of small subgroups. Nevertheless, descriptive data showed no relevant differences between coils and histoacryl.

In the present study, BAE was a safe procedure. Common complications include dissections, arterial perforations, transient dysphagia and chest pain caused by occlusion of esophageal and intercostal vessels, and neurological complications like spinal cord injury $[4,16]$. The reported minor complication rate of $5.0 \%$ (prolonged chest pain, arterial perforation, transient aphasia) is rather low and comparable to previously reported complication rates of $4.9 \%$ to $42 \%[17,18]$. None of the patients suffered from major complications such as spinal cord injury.

CT and angiographic findings are concordant with Kim et al. including ground-glass opacity (72\%) and consolidation (61\%) as the most-specific findings for pulmonary bleeding in CT, and neo-vascularization (85\%) and vessel hypertrophy (45\%) as typical angiographic findings [10]. Active bleeding in angiographic images occurred in only $16 \%$ of cases and should not be used for decision-making for BAE procedure.

Several limitations have to be acknowledged for this study. First, the retrospective analysis of a single-center retrospective study cannot ensure data homogeneity, and the underlying diseases in both subgroups were heterogeneous. Nevertheless, this data demonstrates a significant influence of the underlying disease on the recurrence rate and patient survival. Second, factors possibly af- fecting BAE outcome including supportive medication or others were not considered or evaluated. Third, patients were not divided into subgroups to compare different types of therapy options.

In conclusion, BAE is a safe and highly effective treatment option for patients suffering from hemoptysis. However, the recurrence rate and survival are strongly dependent on the underlying disease, with significantly impaired results in patients suffering from malignant diseases.

\section{References}

1 Andrejak C, Parrot A, Bazelly B et al. Surgical lung resection for severe hemoptysis. The Annals of thoracic surgery 2009; 88: 1556-1565

2 Knott-Craig CJ, Oostuizen JG, Rossouw G et al. Management and prognosis of massive hemoptysis. Recent experience with 120 patients. The Journal of thoracic and cardiovascular surgery 1993; 105: $394-$ 397

3 Ittrich $\mathrm{H}$, Klose $\mathrm{H}$, Adam $\mathrm{G}$. Radiologic management of haemoptysis: diagnostic and interventional bronchial arterial embolisation. Rofo 2015; 187: $248-259$

4 Chen J, Chen LA, Liang ZX et al. Immediate and long-term results of bronchial artery embolization for hemoptysis due to benign versus malignant pulmonary diseases. Am J Med Sci 2014; 348: 204-209

5 Chun JY, Morgan R, Belli AM. Radiological management of hemoptysis: a comprehensive review of diagnostic imaging and bronchial arterial embolization. Cardiovascular and interventional radiology 2010; 33: $240-250$

6 Alexander GR. A retrospective review comparing the treatment outcomes of emergency lung resection for massive haemoptysis with and without preoperative bronchial artery embolization. Eur J Cardiothorac Surg 2014; 45: 251 - 255

7 Shao H, Wu J, Wu Q et al. Bronchial artery embolization for hemoptysis: a retrospective observational study of 344 patients. Chin Med J (Engl) 2015; 128: $58-62$

8 Barben J, Robertson D, Olinsky A et al. Bronchial artery embolization for hemoptysis in young patients with cystic fibrosis. Radiology 2002; 224: $124-130$

9 Chun JY, Belli AM. Immediate and long-term outcomes of bronchial and non-bronchial systemic artery embolisation for the management of haemoptysis. European radiology 2010; 20: 558-565

$10 \mathrm{Kim}$ SW, Lee SJ, Ryu YJ et al. Prognosis and Predictors of Rebleeding After Bronchial Artery Embolization in Patients with Active or Inactive Pulmonary Tuberculosis. Lung 2015; 193: 575-581

$11 \mathrm{Kim}$ YG, Yoon HK, Ko GY et al. Long-term effect of bronchial artery embolization in Korean patients with haemoptysis. Respirology 2006; 11: $776-781$

12 Anuradha C, Shyamkumar NK, Vinu $M$ et al. Outcomes of bronchial artery embolization for life-threatening hemoptysis due to tuberculosis and post-tuberculosis sequelae. Diagnostic and interventional radiology 2012; 18: 96-101

13 Garcia-Olive I, Sanz-Santos J, Centeno C et al. Results of bronchial artery embolization for the treatment of hemoptysis caused by neoplasm. J Vasc Interv Radiol 2014; 25: 221 - 228

14 Woo S, Yoon CJ, Chung JW et al. Bronchial artery embolization to control hemoptysis: comparison of N-butyl-2-cyanoacrylate and polyvinyl alcohol particles. Radiology 2013; 269: 594-602

15 Garcia-Olive I, Sanz-Santos J, Centeno C et al. Predictors of recanalization in patients with life-threatening hemoptysis requiring artery embolization. Arch Bronconeumol 2014; 50: 51-56

16 Lorenz J, Sheth $D$, Patel J. Bronchial artery embolization. Semin Intervent Radiol 2012; 29: 155 - 160

17 Chan VL, So LK, Lam JY et al. Major haemoptysis in Hong Kong: aetiologies, angiographic findings and outcomes of bronchial artery embolisation. The international journal of tuberculosis and lung disease: the official journal of the International Union against Tuberculosis and Lung Disease 2009; 13: 1167-1173

18 Lee S, Chan JW, Chan SC et al. Bronchial artery embolisation can be equally safe and effective in the management of chronic recurrent haemoptysis. Hong Kong medical journal = Xianggang yi xue za zhi/ Hong Kong Academy of Medicine 2008; 14: 14-20 